\title{
PESTICIDE POISONINGS IN 2004-2014 IN ŁÓDŹ, POLAND - AN ANALYSIS OF SELECTED CLINICAL AND SOCIODEMOGRAPHIC PARAMETERS
}

\author{
Anna Krakowiak ${ }^{1}$, Radosław Zajdel ${ }^{2}$, Katarzyna Kobza-Sindlewska ${ }^{3}$, Michał Krakowiak ${ }^{4}$, \\ Anna Piekarska-Wijatkowska ${ }^{3}$
}

${ }^{1}$ Nofer Institute of Occupational Medicine, Łódź, Poland

Toxicology Clinic, Department of Toxicology

${ }^{2}$ University of Lodz, Łódź, Poland

Faculty of Economics and Sociology, Department of Computer Science in Economics

${ }^{3}$ Nofer Institute of Occupational Medicine, Łódź, Poland

Toxicology Clinic, Poison Information Centre

${ }^{4}$ Medical University of Gdansk, Gdańsk, Poland

University Clinical Centre, Neurosurgery Department

\begin{abstract}
Background: Acute pesticide poisonings constitute an important toxicological problem in numerous countries. This report refers to patients treated for poisonings at the Toxicology Unit, Łódź, Poland, in the period 2004-2014. Material and Methods: Data to be analyzed were obtained from medical records of hospitalized people. A group of 24301 patients aged $\geq 15$ were selected. In the group of 149 people poisoned with pesticides ( $0.61 \%$ of all poisoning cases), there were 40 women and 109 men. Logistic regression analysis was used to evaluate the impact of age on suicide attempts using pesticides. Results: Suicide attempts significantly more frequently concerned younger people. In this type of behavior, coumarin derivatives were significantly more often used than organophosphorus compounds or pesticides classified as "others." The patients with suicidal pesticide poisonings stayed in the ward significantly longer than those poisoned unintentionally. Conclusions: In the analyzed population inhabiting an area with a high degree of urbanization, in terms of the place of residence and employment, pesticide poisonings were more common in men than in women. Suicide attempts using pesticides more frequently concerned younger people. Information found in this study may prove useful for education purposes, and also in informing clinicians. Med Pr. 2019;70(6):655-67
\end{abstract}

Key words: epidemiology, suicide attempt, pesticides, logistic regression, intoxication, acute poisonings

Corresponding author: Katarzyna Kobza-Sindlewska, Nofer Institute of Occupational Medicine, Toxicology Clinic, Poison Information Centre, św. Teresy 8, 91-348 Łódź, Poland, e-mail: katarzyna.kobza@imp.lodz.pl

Received: June 5, 2019, accepted: September 10, 2019

\section{INTRODUCTION}

Acute pesticide poisonings constitute an important toxicological problem in numerous countries around the world. Adverse health effects can be observed among patients exposed to pesticides, such as eye or skin irritation, acute poisonings, and chronic diseases [1]. Pesticide poisonings occur not only in the case of agricultural workers, but also in production, storage and distribution workers, as well as in individuals using pesticides for health and hygiene in their households.

Currently, on a global scale, more than 20000 different types of pesticides are produced, containing approx. 900 active substances [2]. Most pesticides, about $80 \%$ of the global production, are used in developed countries. However, the most numerous cases of poison- ing and death from exposure to pesticides are listed in the regions where the remaining small part of the total production is used, i.e., in the least developed countries [3]. Every year, almost 1 million people globally are exposed to accidental pesticide poisonings, about 20000 of which are fatal cases [4].

It is noteworthy that in the European Union countries, including Poland, a decrease in the risks arising from the use of pesticides can be seen. This is a consequence of introducing restrictive legal regulations in this area, within the European Community, over the past 12 years [5]. The effects of the implemented legislative changes include limiting the number of active substances, introducing mandatory registration of plant protection products and biocidal products, as well as performing mandatory assessments of the influence of pesticides on the environment. 
According to professionals in the field of toxicology, the knowledge of the factors determining the occurrence and course of an acute pesticide poisoning is crucial. The ability to identify them is also an important step towards the prevention of acute xenobiotic poisonings. Therefore, the aim of the presented project was to evaluate the incidence of pesticide poisonings among residents of one of the provinces in central Poland over the period of 11 years. Attempts were also made to assess the correlation between the selected sociodemographic and clinical parameters influencing the course of poisoning and the treatment process.

\section{MATERIAL AND METHODS}

The research material covered medical records of the patients treated in the period from January 1, 2004 to December 31, 2014 at the Toxicology Unit (TU) of the Nofer Institute of Occupational Medicine (NIOM) in Łódź. Patients sent to the TU were aged $\geq 15$, with suspected or recognized cases of acute poisoning. The prospective patients of the ward are inhabitants of an area of a high degree of urbanization, namely Łódź, the third largest city in Poland, and of the Łódź Province.

The sociodemographic data collected for the purposes of the research included the following variables: gender, age, place of residence, and marital status. The course of poisoning was characterized by clinical variables, namely the route of poisoning, an instance of poisoning with another toxic agent, a mental illnesses and addictions diagnosed prior to the admission to the ward, the patient's medical status at the time of the admission to the ward (mild, moderate, severe), hospitalization length, and the final treatment outcome. The type of poisoning was also described and identified as either suicidal (intentional self-harm) or accidental. Pesticide groups (the main toxic factor) were established on the basis of their chemical structure:

- organophosphorus compounds,

carbamates,

pyrethroids,

coumarin derivatives,

- other (including polychlorinated insecticides, dipyridyl derivatives).

\section{Ethical approval}

The procedure of the study was approved by the Bioethics Committee at the NIOM in Łódź, Poland (Protocol No. 21/2015).

\section{Statistical analysis}

The results were subjected to statistical analysis, including some multidimensional tests. Normal distribution was assessed with the Shapiro-Wilk test. As the distribution of the characteristics tested in the population was not within the norm, and both the qualitative and quantitative data were analyzed, nonparametric tests including the Kruskal-Wallis ANOVA, Pearson's $\chi^{2}$ test, the Maximum-Likelihood $\chi^{2}$ test $\left(\chi^{2} M L\right)$, and the Mann-Whitney $U$ test were used. The authors also performed logistic regression creating a logit model, as shown in the formula:

$$
\begin{gathered}
\text { Logit } \mathrm{P}=1.65+0.35 \times \mathrm{se} \times+0.03 \times \text { age }-0.23 \times \\
\text { marital status }
\end{gathered}
$$

General descriptive measures $(\mathrm{M}, \mathrm{Me}, \mathrm{SD})$ were also used. The statistical significance was set at $\mathrm{p}<0.05$.

\section{RESULTS}

In the research period, a total of 24301 patients were hospitalized at the TU NIOM. In the group of 149 people poisoned with pesticides, accounting for $0.61 \%$ of all poisoning cases, there were 40 women and 109 men ( $0.16 \%$ and $0.45 \%$, respectively). The average age of the patients treated as a result of pesticide poisoning was 46.6. In the case of women, the data relating to age were slightly higher, the average age being 54.5 , the min. age: 18 , and the max age: 88 ; while for men: the average was 43.7 , the min. age: 15 , and the max age: 79 .

\section{Hospitalization length}

The detailed descriptive data regarding hospitalization length, accounting for the grouping factors and the results of the identified statistically significant dependencies, are shown in Table 1. It was shown that the length was significantly shorter for the patients living in Łódź, as opposed to the patients living in the Łódź Province (3.5 days vs. $7.5, \mathrm{p}=0.000970$ ).

The patients admitted to the TU in generally good condition spent significantly less time in the ward than those admitted in fair or serious condition (3.5 vs. 7.1, $\mathrm{p}=0.000025 ; 3.5$ vs. $18.4, \mathrm{p}=0 ; \mathrm{p}=0.000009$ ). Similarly, hospitalization length was significantly shorter in the patients admitted to the ward in fair condition, compared to the ones in serious condition (7.1 vs. 18.4, $\mathrm{p}=0.029824$ ).

The patients additionally poisoned with ethanol spent significantly more time in the ward than the patients 


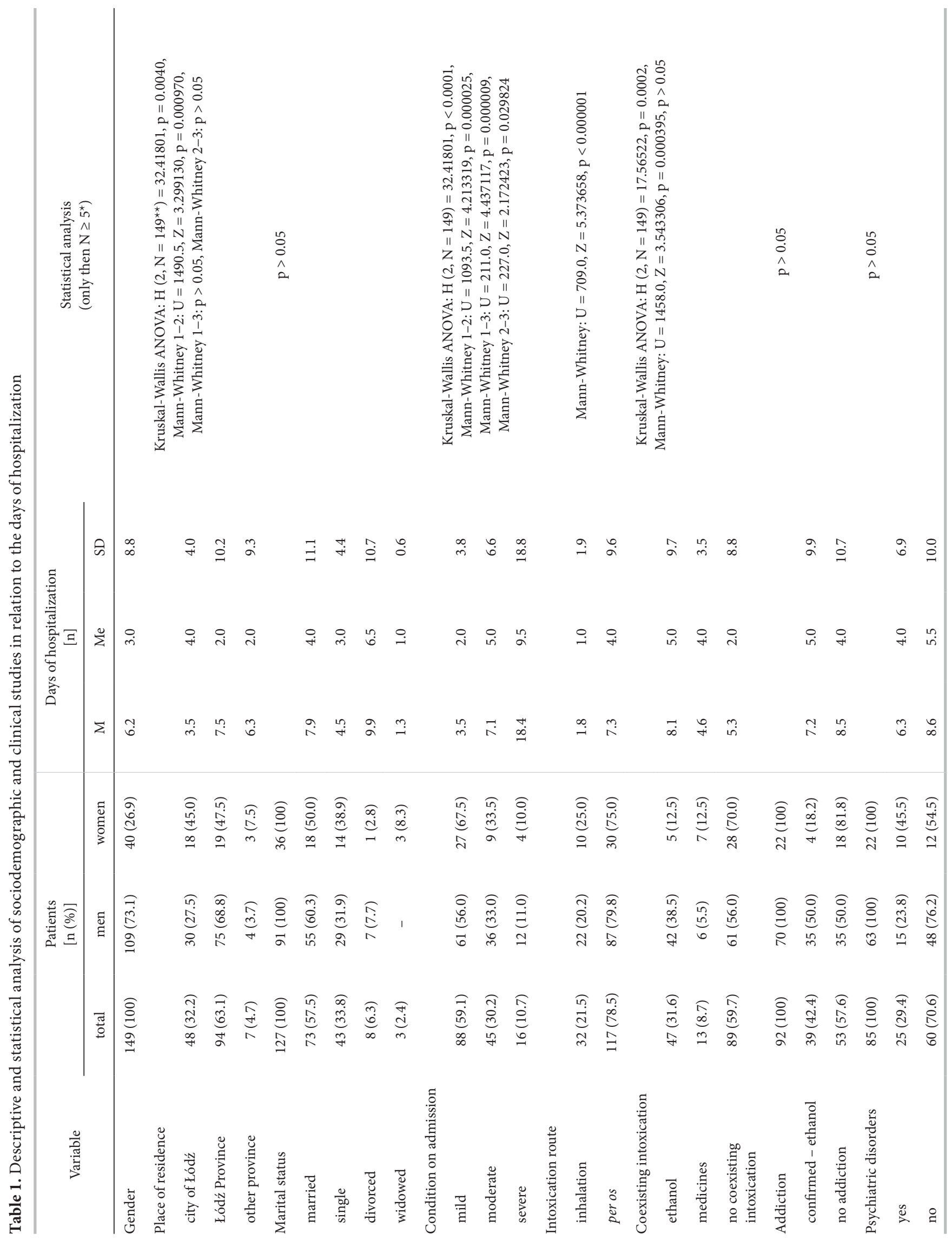




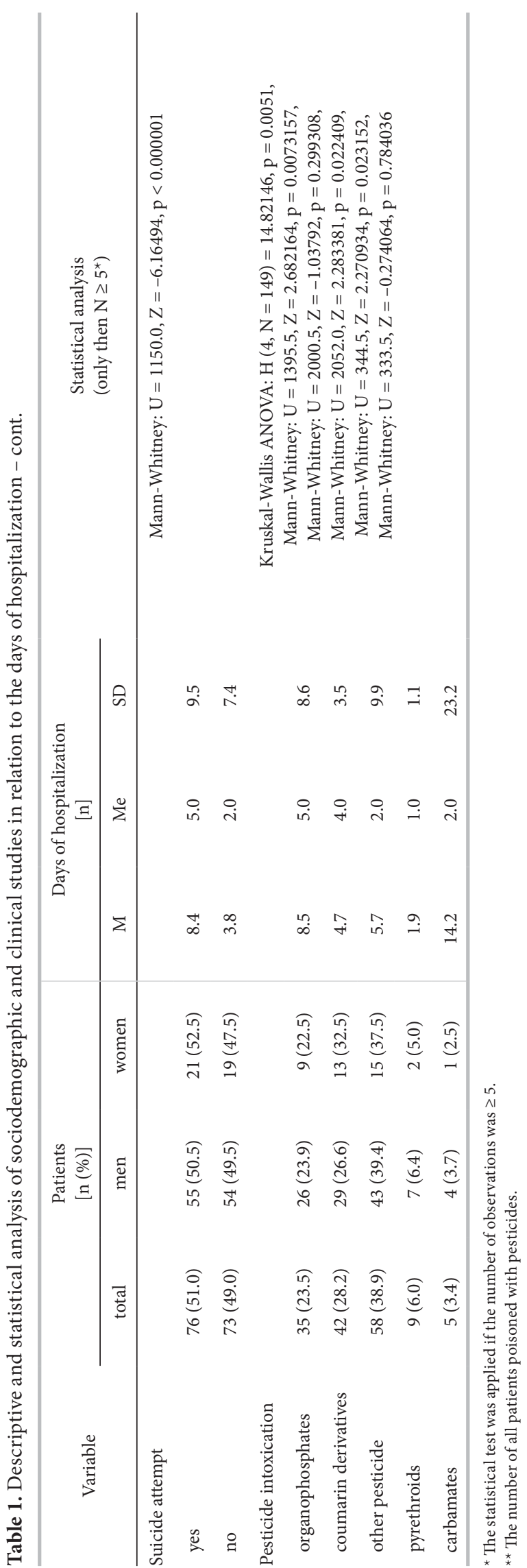

with no additional poisoning (8.1 vs. 5.3, $\mathrm{p}=0.000395$ ). Similarly, the patients poisoned by the oral route were hospitalized longer than those poisoned by inhalation (7.3 vs. $1.8, \mathrm{p}<0.000001$ ).

The patients with suicidal pesticide poisoning stayed in the ward significantly longer than the patients poisoned unintentionally ( 8.4 vs. $3.8, \mathrm{p}<0.000001$ ).

The analysis of the correlation between hospitalization length and the kind of the pesticide showed that hospitalization length was significantly longer than average (6.2) in the patients poisoned with organophosphorus compounds $(8.5, \mathrm{p}=0.007315)$.

There was no correlation between hospitalization length and the day of the month on which the poisoning occurred, the marital status, a confirmed diagnosis of alcohol addiction or a mental illness, or the kind of the toxic substance, in the case of the ingestion of coumarin derivatives or carbamates $(p>0.05)$.

\section{Patients' medical state on admission}

A thorough descriptive and statistical analysis of the factors affecting the condition of the patients in the admission room is presented in Table 2.

Married people were significantly more often in fair, rather than good, condition, compared to single patients (30:34 vs. $6: 32, \mathrm{p}=0.031)$.

The poisoning route had a significant impact on the patients' status on admission. The patients poisoned by inhalation were admitted in good condition significantly more often than in fair condition, compared to the patients poisoned by means of oral ingestion (26:5 vs. 62:40, $\mathrm{p}=0.0306$ ). Due to the numbers, the patients in serious condition were not researched.

A significant correlation was shown between the patient's condition at the time of admission and the type of the substance taken, as an additional factor. It was found that the patients additionally poisoned with alcohol came to the admission room in fair condition much more often than in good condition, compared with the patients without additional poisoning (23:20 vs. 16:65, $\mathrm{p}=0.0002$ ).

The suicidal intention of pesticide poisoning significantly influenced the patients' status on admission. It was shown that the patients making a suicide attempt were significantly more often in both fair (30:34 vs. 15:54, $\mathrm{p}=0.0022)$ and serious condition (12:34 vs. $4: 54, \mathrm{p}=$ $0.0155)$, compared to those without the intentional selfharm attempt.

The patients' status on admission did not depend on gender, the place of residence, the type of the pesticide 


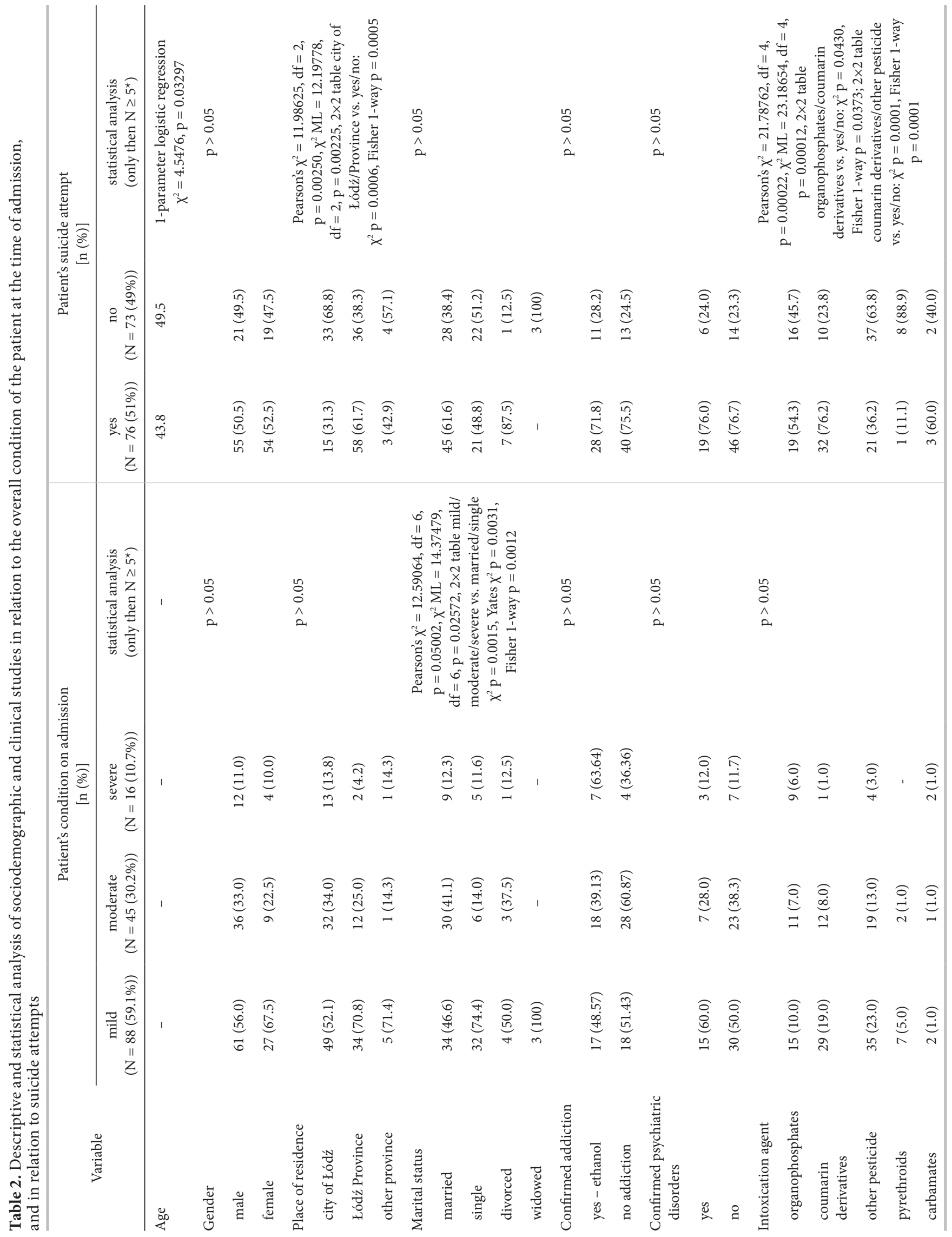




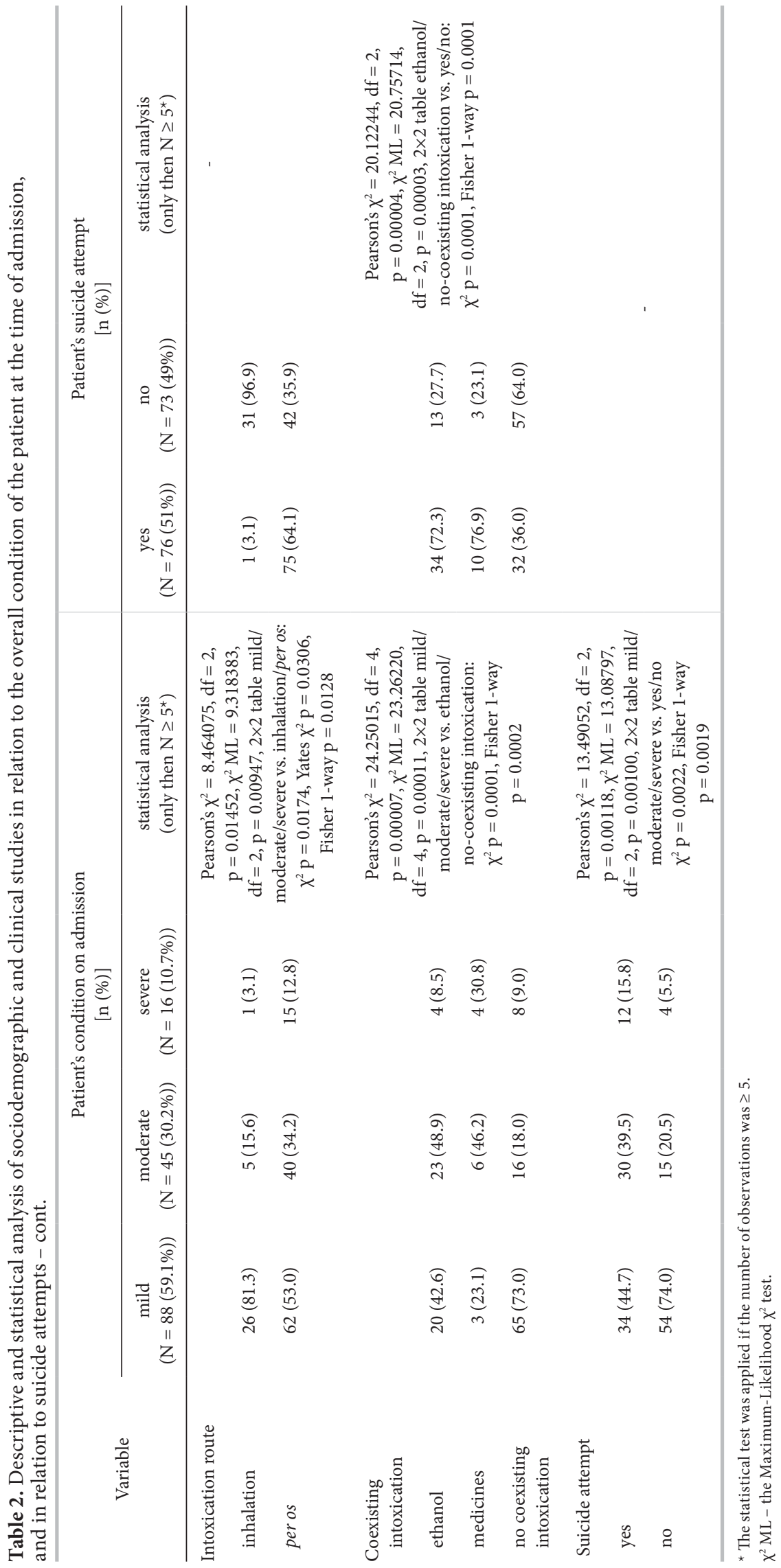


used, or a confirmed alcohol addiction or a mental illness $(\mathrm{p}>0.05)$.

Neither the effect of alcohol poisoning on the incidence of a serious medical condition, nor the impact of additional prescription drug poisoning on the patients' status on admission were shown ( $p>0.05)$.

\section{Suicide attempts and unintentional poisonings}

The paper examined the effects of various factors on suicide attempts using pesticides. A thorough descriptive and statistical analysis of the factors affecting the variable researched is presented in Table 3.

The impact of age on suicide attempts using pesticides was evaluated by means of the logistic regression analysis which showed that this type of behavior significantly more frequently concerned younger people (43.8 years old), whereas the average age of people poisoned unintentionally was 49.5 years $(\mathrm{p}=0.03297)$.

The married patients clearly more often than the single patients made a suicide attempt (61.6\% vs. $48.8 \%)$; however, the isolated $\chi^{2}$ test did not show significance ( $p>0.05)$. Nevertheless, in the 3-factor logistic regression model, the significance of this impact was on the borderline $(\mathrm{p}=0.049)$.

Incidental poisonings occurred significantly more frequently among the inhabitants of the city of Łódź than among the residents of the Łódź Province (68.8\% vs. $38.3 \%, \mathrm{p}=0.0005)$.

In suicide attempts, coumarin derivatives were significantly more often used than organophosphorus compounds or pesticides classified as "others" (76.2\% vs. $54.3 \%$ and $36.2 \%, p=0.0373$ and $p=0.0001)$. These patients almost always used the oral ingestion (75 vs. 1 ).

In suicide attempts, alcohol was additionally used significantly more often $(72.3 \%$ vs. $36.0 \%, p=0.0001)$.
The patients' sex, marital status, confirmed diagnosis of an addiction or mental illness did not influence significantly a suicide attempt with the use of pesticides $(p>0.05)$.

The analysis of the parameters of the logistic regression model (Table 3 ) showed that the variable "sex" did not have a significant impact on attempting suicide $(\mathrm{p}>0.05)$.

In turn, the variables "age" and "marital status" had a statistically significant effect ( $\mathrm{p}=0.010107, \mathrm{p}=$ 0.031508 ) on the researched phenomenon. The odds ratio for age revealed that suicide was slightly more often attempted by people of a slightly younger age (1.03). In turn, it was about 1.3 times more likely that the patients using pesticides for their suicide attempt were married.

\section{The final hospitalization outcome}

The analysis of the correlation between the treatment outcome and the patients' status at the time of their admission to hospital showed that, despite numerous differences (Table 4), there was a greater number of patients admitted in good overall condition, leaving the hospital at their own request, compared to the patients discharged from the hospital with a recommendation that their treatment be continued by a general practitioner $(27.3 \%$ vs. $12.5 \%, \mathrm{p}=0.454)$, and this finding appeared to be statistically significant. Also, considerably more patients hospitalized in fair condition (22.2\%) were referred to the local outpatient clinic for continued treatment, compared to the number of patients discharged at their own request (11.1\%).

The type of the pesticide used had a statistically significant effect on the termination of hospitalization (Table 4). The patients poisoned with "other" pesticides significantly more often left the hospital at their own

Table 3. Results of logistic regression analysis, the correlation between suicide attempts $(\mathrm{N}=116)$ with the use of pesticides, and gender, age and marital status

\begin{tabular}{lcllc}
\hline \multirow{2}{*}{ Variable } & \multicolumn{4}{c}{ Logistic regression analysis } \\
\cline { 2 - 5 } evaluation & constant B0 & gender & age & marital status \\
SE & -1.648632 & 0.3533353 & 0.033345 & -0.233582 \\
$\mathrm{p}$ & 1.09781 & 0.4530208 & 0.01276331 & 0.1073711 \\
Wald $\chi^{2}$ & 0.1357255 & 0.4369164 & 0.01010651 & 0.03150757 \\
$\mathrm{p}$ & 2.255243 & 0.6083277 & 6.825505 & 4.73265 \\
OR & 0.1331724 & 0.4354239 & 0.008990712 & 0.02960255 \\
\hline
\end{tabular}

Logistic regression (logit) N zeros: 73 ones: 54 , dependent variable: suicidal, loss: greatest probability, mean square error, total loss: $81.730973659, \chi^{2}(3)=9.7442$, $\mathrm{p}=0.02088$, modeled $\mathrm{p}$.

B0 - y-intercept. 


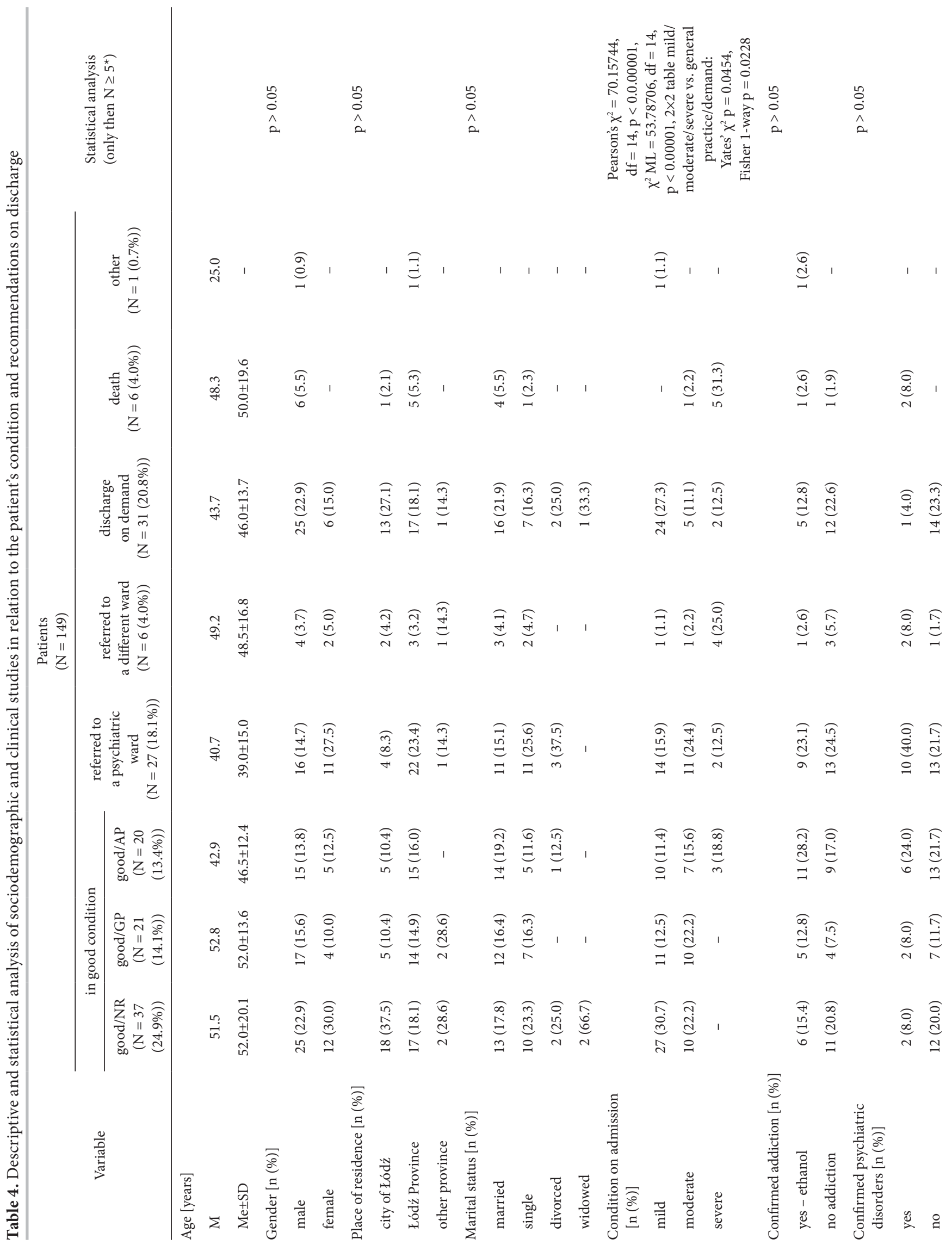




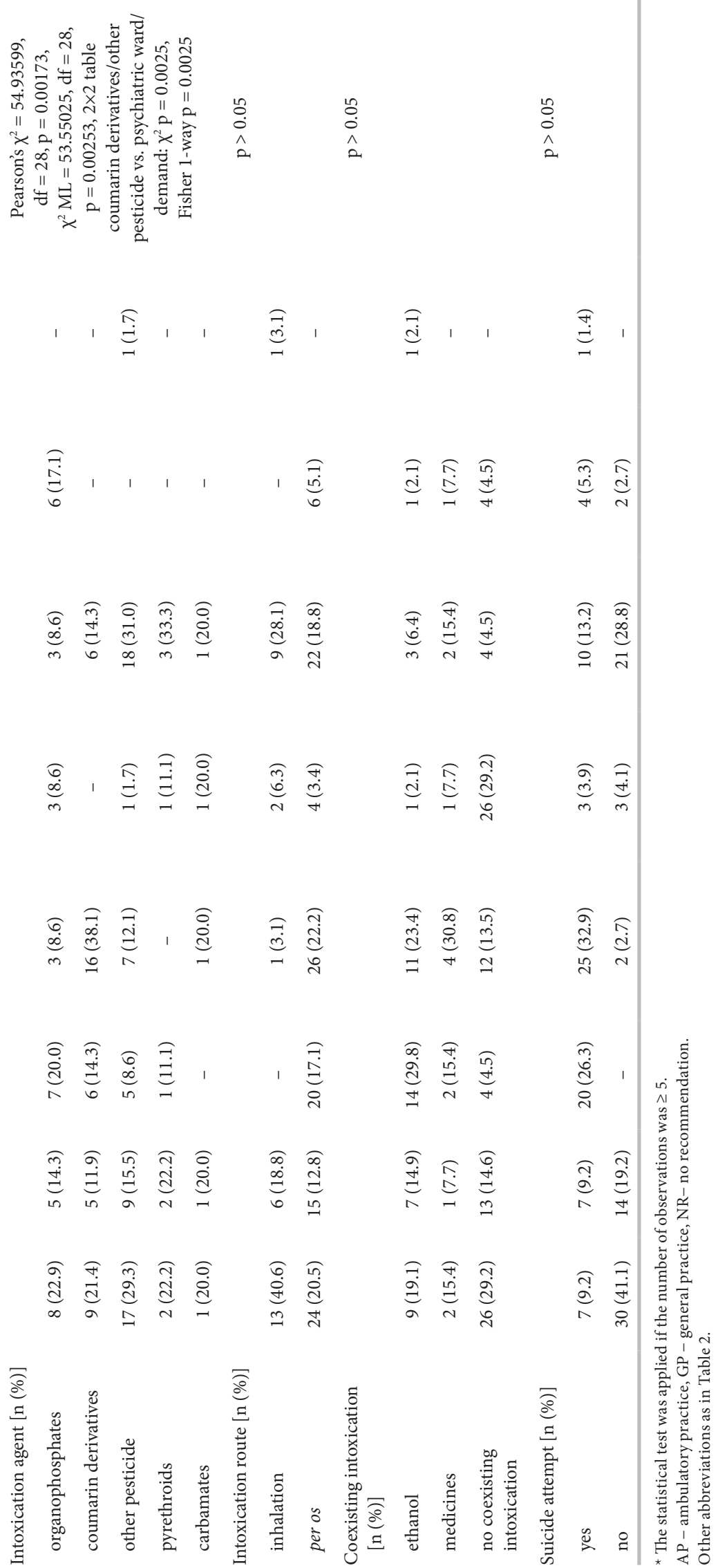


Table 5. Statistical analysis of the correlation between the patient's referral to the psychiatrist and other examined factors

\begin{tabular}{|c|c|c|}
\hline \multirow[t]{2}{*}{ Variable } & \multicolumn{2}{|c|}{$\begin{array}{l}\text { Patients referred to the psychiatrist } \\
\qquad[\mathrm{n}(\%)]\end{array}$} \\
\hline & yes & no \\
\hline \multicolumn{3}{|l|}{ Place of residence } \\
\hline city of Łódź & $9(25.7)$ & $26(74.3)$ \\
\hline Łódź Province & $37(48.1)$ & $40(51.9)$ \\
\hline \multirow[t]{2}{*}{ other province } & $1(16.7)$ & $5(83.3)$ \\
\hline & \multicolumn{2}{|c|}{$\begin{array}{c}\text { Pearson's } \chi^{2}=6.425128, \mathrm{df}=2, \mathrm{p}=0.04025 \\
\chi^{2} \mathrm{ML}=6.729365, \mathrm{df}=2, \mathrm{p}=0.03457 \\
2 \times 2 \text { table city of } \text { Eódź/Province vs. yes } / \text { no: } \chi^{2} \mathrm{p}=0.0266 \text {, Fisher } 1 \text {-way } \mathrm{p}=0.0205\end{array}$} \\
\hline \multicolumn{3}{|l|}{ Intoxication agent } \\
\hline organophosphates & $10(31.3)$ & $22(68.7)$ \\
\hline coumarin derivatives & $22(61.1)$ & $14(38.9)$ \\
\hline other pesticide & $12(30.0)$ & $28(70.0)$ \\
\hline pyrethroids & $1(16.7)$ & $5(83.3)$ \\
\hline \multirow[t]{2}{*}{ carbamates } & $2(50.0)$ & $2(50.0)$ \\
\hline & \multicolumn{2}{|c|}{$\begin{array}{l}\text { Pearson's } \chi^{2}=10.91460, \mathrm{df}=4, \mathrm{p}=0.02754 \\
\quad \chi^{2} \mathrm{ML}=10.98268, \mathrm{df}=4, \mathrm{p}=0.02676 \\
\text { osphate/coumarin vs. yes/no: } \chi^{2} \mathrm{p}=0.0145 \text {, Fisher } 1 \text {-way } \mathrm{p}=0.0128 \\
\text { n/other pesticide vs. yes/no: } \chi^{2} \mathrm{p}=0.0068 \text {, Fisher } 1 \text {-way } \mathrm{p}=0.0061\end{array}$} \\
\hline
\end{tabular}

$\chi^{2} \mathrm{ML}$ - the Maximum-Likelihood $\chi^{2}$.

request than those who were poisoned with coumarin derivatives $(31.0 \%$ vs. $15.5 \%, \mathrm{p}=0.0025)$. The remaining compounds were not relevant or their numbers prevented a reliable statistical analysis.

Hospitalization outcomes did not depend on the patients' sex, place of residence, marital status, or the existence of an addiction or a mental illness ( $p>0.05$ ). Similarly, despite the apparent relative differences in the way the patients were discharged from the hospital, depending on the poisoning route and the existence of an additional factor, as well as intended self-harm (suicidal poisoning), this impact was not significant ( $\mathrm{p}>0.05)$.

A separate analysis was devoted to the impact of the variables on the patient being referred to the psychiatrist, either in an outpatient clinic or an inpatient ward (Table 5). It was shown that the place of residence and the type of the toxic substance had a significant impact; the patients living in the Łódź Province were significantly more often directed to the psychiatrist than the inhabitants of the city of Łódź (48.1\% vs. 25.7\%, $\mathrm{p}=0.0205)$. The patients poisoned with organophosphorus compounds were significantly less often referred to the psychiatrist than the ones poisoned with coumarin derivatives $(31.3 \%$ vs. $61.1 \%, p=0.0128)$. Other compounds were not statistically significant $(\mathrm{p}>0.05)$.

\section{DISCUSSION}

Pesticides are varied in terms of the structure and usage of chemical substances, their main purpose being to provide protection against pests [6]. The use of pesticides causes environmental pollution and accidental exposure of certain groups of people to their harmful effects [7]. In developing countries, environmental pollution caused by pesticides is high due to their wide use, while the lack of control and the adequate protection measures increases the incidence of negative health effects among people [8].

In a general population, the scale of the pesticide risk exposure is relatively small. However, certain groups of people are particularly exposed to the harmful effects of pesticides (e.g., farmers and their families, people living near areas where pesticides are regularly used) [9].

It is very difficult to estimate the number of acute pesticide poisoning cases in Poland. This is mainly due to an imperfect way of reporting and collecting information on acute poisoning cases across the country. Moreover, reliable sources providing the necessary data in this field are missing.

In the analyzed population inhabiting an area with a high degree of urbanization, in terms of the place of 
residence and employment, pesticide poisonings were more common in men than in women.

In the research conducted by Przybylska [10,11], among people dealing with plant protection products in Poland, in the years 2000 and 2002, it was observed that the incidence of poisonings with these products was twice lower in women than in men (respectively, 0.19 and 0.37 per 100000 inhabitants). In the research, a high incidence of poisonings in men aged 50-69, living in rural areas, was highlighted (0.89). The most common cause of poisoning described by the author $[10,11]$ is the careless handling of products (easy access, an inappropriate poison label or inappropriate protective clothing at work).

The results collected in the publication on poisonings with biocides, i.e., products intended for the control of harmful organisms outside plant production, confirmed that this issue concerned men more frequently than women. The exposure took place in domestic conditions, and the most common cause of exposure to biocides was contact with various forms of rodenticides [12].

A higher incidence of pesticide poisonings among men has also been noted in countries such as Brazil, Taiwan and Sri Lanka [13-15]. According to the authors of the paper on pesticide poisonings in Brazil [13], accidental poisonings with this factor occurred mainly in small farms. This could be due to a low awareness of people using pesticides in relation to the potential health risks.

Cultural factors are pointed out by the authors researching pesticide poisonings in South Africa, where women were poisoned more often than men $[16,17]$. Incidents in which women were more numerous occurred during field work or as a result of the ingestion of food contaminated by pesticides.

In the publication concerning patients hospitalized at the University Hospital in Fez (Morocco), it was also observed that more women were poisoned with pesticides intentionally. According to the authors, this situation could have been influenced by psychological and social factors [16].

\section{Hospitalization length}

The average duration of stay at the TU NIOM in Łódź, as a result of a pesticide poisoning, amounted to 6.2 days. The results of similar studies indicate a similar average hospitalization length: approx. 1 week $[10,11]$. The patients poisoned with organophosphorus compounds stayed at the TU NIOM significantly longer: 8.5 days. Pesticides from this group as well as dipyridyl deriva- tives, responsible for the longest hospitalization length, are indicated by the authors of the study regarding the problem of pesticide poisonings in Poland in the 1990s [18].

The patients additionally poisoned with ethanol required longer hospitalization, which is confirmed in the available literature $[19,20]$. The duration of hospitalization in the case of people poisoned with pesticides, and at the same time poisoned with alcohol and often also addicted, is longer because of the influence of 2 toxic substances. In addition, pesticides dissolve in alcohol very well, hence the absorption from the gastrointestinal tract is facilitated [21].

An important factor in terms of hospitalization length was the route by which the toxic substance was taken, as the patients poisoned by oral ingestion were hospitalized longer than those poisoned by inhalation. Descriptions of per os pesticide poisoning cases were also dominant in the available literature $[10,11,14,20]$. In a study performed in Poland in 2000, they represented $74.8 \%$ of the total number of poisoning cases, while in $2002-66 \%$ [10,11].

The results presented in the paper indicate that the patients living in Łódź were hospitalized over 2 times shorter than the inhabitants of the Łódź Province. It should be presumed that the shorter duration of hospitalization in the case of the inhabitants of Łódź was due to the place of residence, resulting in a shorter time needed to reach the TU, and thus the possibility to introduce proper treatment faster.

In the patients attempting suicide, hospitalization length was twice longer. At the same time, it was found that hospitalization length did not depend on the month in which the event occurred, or on the marital status, a confirmed alcohol addiction or a mental illness diagnosis. In the literature on the subject matter, the highest number of pesticide poisoning cases was recorded in spring and summer months, with the peak occurring in May [10,11]. A greater incidence of poisoning cases in this period is largely due to agricultural work, and these cases can be classified as occupational poisonings (agricultural production, sanitary actions), but incidental poisonings may also occur (deratization, pest control in households, accidental ingestion).

\section{Suicide attempts vs. unintentional poisonings}

In the presented research, more than half of the cases of pesticide poisonings were classified as suicide attempts. In a study analyzing acute pesticide poisonings, conducted in 1994-1995 in Poland, 66\% of pesticide poison- 
ing cases included suicide attempts, and 31.5\% unintentional poisonings. The percentage of suicidal poisonings with the use of pesticides was found to be lower in 2000, with $28 \%$ of poisoning cases, and in $2002-35.9 \%$ of all poisonings in Poland [10,11].

A pilot study conducted in Cameroon [22] showed that among the group poisoned with pesticides, $78 \%$ constituted accidental poisonings, $12 \%$ were suicidal poisonings, and $4 \%$ criminal poisonings.

Intentional pesticide poisonings are also a significant problem in numerous countries in the world $[14,15]$. In Taiwan, over $60 \%$ of pesticide poisonings with organophosphorus compounds were suicidal [14]. Pesticides from the same group were the cause of more than $40 \%$ of suicide deaths among people over the age of 25 , living in the agricultural regions of Sri Lanka [15].

In the study, it was found that significantly more suicide attempts were made by younger people (average age: 43.8) compared with unintentional poisonings (average age: 49 ). This finding corresponds with the results of a survey carried out in Poland at the turn of the 1980s and 1990s, in which it was observed that among the people intentionally poisoned with pesticides (suicide attempts) the age group of 25-44 dominated. Among the people poisoned accidentally, the most represented age was 35-54 [23].

The results presented in the paper indicate that the pesticides most often used in suicide attempts were coumarin derivatives, organophosphorus compounds, and other pesticides. In a study conducted in 2000, analyzing poisonings with plant protection products only [10], insecticides from the pyrethroids group caused $37.4 \%$ of poisoning cases, organophosphorus pesticides $-13.1 \%$, carbamates $-9.3 \%$, and others $-14.0 \%$. However, in less developed countries, poisonings most frequently occurred as a result of exposure to organophosphorus pesticides [17,24-29].

\section{CONCLUSIONS}

In the analyzed population inhabiting an area with a high degree of urbanization, in terms of the place of residence and employment, pesticide poisonings were more common in men than in women. Suicide attempts using pesticides more frequently concerned younger people. Coumarin derivatives were the most frequent type of the toxic agent responsible for all pesticide suicidal poisoning cases in Łódź, Poland. Information found in this study may prove useful for education purposes, and also in informing clinicians.

\section{REFERENCES}

1. Sanborn M, Kerr KJ, Sanin LH, Cole DC, Bassil KL, Vakil C. Non-cancer health effects of pesticides: systematic review and implications for family doctors. Can Fam Physician. 2007;53:1712-20.

2. Jeyaratnam J. Acute pesticide poisoning: A major global health problem. World Health Stat Q. 1990;43(3):139-44.

3. Piechowicz B, Stawarczyk K, Stawarczyk M. Hazard posed by using chemicals for plant protection. Bezp Pr Nauk Prakt. 2012;3:2-9.

4. Pimnetel D. Green revolution agriculture and chemicals hazards. Sci Total Environ. 1996;188(1):86-98, https://doi. org/10.1016/S0048-9697(96)90512-4.

5. [Act on Plant Protection of 18 December 2003, consolidated text. J Laws 2016 No. 2246, item 2041] [Internet]. Kancelaria Sejmu RP, 2019 [cited 2019 Jun 5]. Available from: http://prawo.sejm.gov.pl/isap.nsf/DocDetails. xsp?id=WDU20160002041. Polish.

6. Costa C, Gangemi S, Giambo F, Rapisarda V, Caccamo D, Fenga C. Oxidative stress biomarkers and paraoxonase 1 polymorphism frequency in farmers occupationally exposed to pesticides. Mol Med Rep. 2015;12:6353-7, https:// doi.org/10.3892/mmr.2015.4196.

7. Kapka-Skrzypczak L, Cyranka M, Skrzypczak M, Kruszewski M. Biomonitoring and biomarkers of organophosphate pesticides exposure - state of the art. Ann Agric Environ Med. 2011;18:294-303.

8. Coronado GD, Holte S, Vigoren E, Griffith WC, Barr DB, Faustman E., et al. Organophosphate pesticides exposure and residential proximity to nearby fields: evidence for the drift pathway. J Occup Environ Med. 2011;53(8):884-91, https://doi.org/10.1097/JOM.0b013e318222f03a.

9. Mehrpour O, Karrari P, Zamani N, Tsatsakis AM, Abdollahi M. Occupational exposure to pesticides and consequences on male semen and fertility: a review. Toxicol Lett. 2014; 230:146-56, https://doi.org/10.1016/j.toxlet.2014.01.029.

10. Przybylska A. Poisoning caused by chemicals for plant protect in Poland in 2000. Przegl Epidemiol. 2002;56:311-7.

11. Przybylska A. Poisoning caused by chemicals for plant protect in Poland in 2002. Przegl Epidemiol. 2004;58:111-21.

12. Łukasik-Głebocka M, Nawrocka K. Biocide exposures reported to Poznan Toxicological Information Center. Przegl Lek. 2011;68(8):440-3.

13. Recena MCP, Pires DX, Caldas ED. Acute poisoning with pesticides in the state of Mato Grosso do Sul, Brazil. Sci Total Environ. 2006;357:88-95, https://doi.org/10.1016/j.scitotenv.2005.04.029.

14. Lin TJ, Walter FG, Hung DZ, Tsai JL, Hu SC, Chang JS, et al. Epidemiology of organophosphate pesticide poison- 
ing in Taiwan. Clin Toxicol. 2008;46:794-801, https://doi. org/10.1080/15563650801986695.

15. Eddleston M, Gunnell D, Karunaratne A, De Silva DA, Rezvi Sheriff MH, Buckley NA. Epidemiology of intentional self-poisoning in rural Sri Lanka. Br J Psychiatry. 2005;187:583-4, https://doi.org/10.1192/bjp.187.6.583.

16. Boukatta B, El Bouazzaoui A, Guemoune R, Houari N, Sanae A, Sbai H, et al. An epidemiological study of adult acute poisoning in Fez: Morocco. JCT. 2014;4(6):1-5, https:// doi.org/10.4172/2161-0495.1000219.

17. Malangu N, Ogunbanjo GA. A profile of acute poisoning at selected hospitals in South Africa. South Africa Epidemiol Infect. 2009;24(2):14-6, https://doi.org/10.1080/10158782. 2009.11441343.

18. Kotwica M, Czerczak S, Rogaczewska A. The pattern of acute poisoning with pesticides in Poland during the periods 1989-1990 and 1994-1995. Przegl Lek. 1997;54(10):689-92.

19. Walesiuk A, Wojewódzka-Żelezniakowicz M, Halim N, Łukasik-Głębocka M, Czaban LS, Myćko G, et al. Intoxications by chemicals for plant protection. Progress Med. 2010;9:729-35.

20. Brzeski S, Sodolski W, Wójcik A. Acute pesticide poisonings treated in the Department of Clinical Toxicology of the Institute of Agricultural Medicine in Lublin. In: Nazimek T, Solecki L, editors. Chemical hazards in agriculture. Current status and prospects. Lublin: Institute of $\mathrm{Ru}-$ ral Health; 2006, pp. 301-4.

21. Kanchan T, Ritesh G, Menezes TS, Mohan K. Toxicoepidemiology of fatal poisonings in Southern India. J Forensic Leg Med. 2010;17:344-7, https://doi.org/10.1016/ j.jflm.2010.05.006.
22. Pouokam GB, Album WL, Ndikontar AS, Sidatt MEH. A pilot study in Cameroon to understand safe uses of pesticides in agriculture, risk factor for farmers' exposure and management of accidental cases. Toxics. 2017;5:4-15, https:// doi.org/10.3390/toxics5040030.

23. Panasiuk L, Parzycki P. Poisoning of plant protection products in Poland. In: Nazimek T, Solecki L, editors. Chemical hazards in agriculture. Current status and prospects. Lublin: Institute of Rural Health; 2006, pp. 291-8.

24. Abdollahi Z, Taghizadeh F, Zarghami M. The epidemiology of phosphine self-poisoning in Sari, Iran, 2008-2010. Advan Biol Res. 2013;7(6):3014.

25. Gupta R, Baghel PK, Gupta H, Jain MK, Khadanga S, Tagore $\mathrm{S}$, et al. Changing epidemiology of poisoning in Central India: shifting poles from male farmers to young house wives. Int J Med Res Rev. 2016;4(4):575-81.

26. Konradsen F. Acute pesticide poisoning - a global public health problem - secondary publication. Dan Med Bull. 2007;54(1):58-59.

27. Eddleston M, Phillips MR. Self-poisoning with pesticides. BMJ. 2004;328:42-44, https://doi.org/10.1136/bmj.328. 7430.42 .

28. Eddleston M, Karalliedde L, Buckley N, Fernando R, Hutchinson G, Isbister G. Pesticide poisoning in the developing world-a minimum pesticides list. Lancet. 2002;360: 1163-67, https://doi.org/10.1016/S0140-6736(02)11204-9.

29. Lamsal DR. Acute pesticide poisoning: review of patients attending at emergency department in Citwan Medical College. JCMC. 2013;3(3):62-4, https://doi.org/10.3126/ jcmc.v3i1.8469.

This work is available in Open Access model and licensed under a Creative Commons Attribution-NonCommercial 3.0 Poland License - http://creativecommons.org/licenses/by-nc/3.0/pl/deed.en. 